\title{
Rip Current Observations via Marine Radar
}

\author{
Merrick C. Haller, M.ASCE${ }^{1}$; David Honegger²; and Patricio A. Catalan ${ }^{3}$
}

\begin{abstract}
New remote sensing observations that demonstrate the presence of rip current plumes in X-band radar images are presented. The observations collected on the Outer Banks (Duck, North Carolina) show a regular sequence of low-tide, low-energy, morphologically driven rip currents over a 10-day period. The remote sensing data were corroborated by in situ current measurements that showed depth-averaged rip current velocities were $20-40 \mathrm{~cm} / \mathrm{s}$ whereas significant wave heights were $H_{s}=0.5-1 \mathrm{~m}$. Somewhat surprisingly, these low-energy rips have a surface signature that sometimes extends several surf zone widths from shore and persists for periods of several hours, which is in contrast with recent rip current observations obtained with Lagrangian drifters. These remote sensing observations provide a more synoptic picture of the rip current flow field and allow the identification of several rip events that were not captured by the in situ sensors and times of alongshore deflection of the rip flow outside the surf zone. These data also contain a rip outbreak event where four separate rips were imaged over a 1-km stretch of coast. For potential comparisons of the rip current signature across other radar platforms, an example of a simply calibrated radar image is also given. Finally, in situ observations of the vertical structure of the rip current flow are given, and a threshold offshore wind stress $\left(>0.02 \mathrm{~m} / \mathrm{s}^{2}\right)$ is found to preclude the rip current imaging. DOI: 10.1061/(ASCE)WW.1943-5460.0000229. (C) 2014 American Society of Civil Engineers.
\end{abstract}

Author keywords: Rip currents; Radar; Surf zone; Nearshore hydrodynamics.

\section{Introduction}

Rip currents are distinct, offshore-directed currents that are a danger to swimmers and the most common cause of lifeguard rescues on bathing beaches (Fletemeyer and Leatherman 2010). Rip currents are also an important exchange mechanism between nearshore waters and the inner shelf [see Dalrymple et al. (2011) for a review]. Unfortunately, for two reasons, rip currents are often difficult to forecast. First, rips can be very transient: they pop up into existence rather abruptly and then disappear minutes later on long uniform stretches of beach (Johnson and Pattiaratchi 2004). In these cases, the rips appear where and when the nearshore wave group structure has just the right characteristics; therefore, rips generally do not recur at the same place twice. There are other conditions where rips are more persistent and stationary, such as with long-crested swell incidents on a long straight bar with a gap (rip channel). These are morphologic rips, and the difficulty in forecasting them arises from the difficulty in sufficiently forecasting the morphology (in places where real-time bathymetry is not available). Because of these challenges in forecasting rip current occurrence, there is a need for improved rip current observation systems.

\footnotetext{
${ }^{1}$ Associate Professor, School of Civil and Construction Engineering, Oregon State Univ., 220 Owen Hall, Corvallis, OR 97331 (corresponding author). E-mail: merrick.haller@oregonstate.edu

${ }^{2}$ Graduate Research Assistant, School of Civil and Construction Engineering, Oregon State Univ., 220 Owen Hall, Corvallis, OR 97331.

${ }^{3}$ Assistant Professor, Departamento de Obras Civiles, Universidad Técnica Federico Santa María, Avenida España 1680, Valparaíso 2390206, Chile; and Associate Researcher, Centro Nacional de Investigación para la Gestión Integrada de Desastres Naturales, Universidad Técnica Federico Santa María, Avenida España 1680, Valparaíso 2390206, Chile; and Associate Researcher, Centro Científico Tecnológico de Valparaíso, Universidad Técnica Federico Santa María, Avenida España 1680, Valparaíso 2390206, Chile.

Note. This manuscript was submitted on December 19, 2012; approved on July 27, 2013; published online on July 30, 2013. Discussion period open until August 1, 2014; separate discussions must be submitted for individual papers. This paper is part of the Journal of Waterway, Port, Coastal, and Ocean Engineering, Vol. 140, No. 2, March 1, 2014. CASCE, ISSN $0733-$ 950X/2014/2-115-124/\$25.00.
}

Smith (2008) pointed out that the spatial scales of rip current flows, which are of the order 10-1,000 m, are undersampled by traditional in situ methods. On the other hand, MacMahan et al. (2010) obtained a somewhat synoptic picture of rip current flow using a fleet (30) of Global Positioning System-equipped drifters. More subjective measures, such as lifeguard rescues and visual observations, have also been used for rip current identification with some success (Scott et al. 2009; Dusek and Seim 2013). Alternately, remote sensing methods offer the potential for frequent collections of synoptic and quantitative observations in the nearshore (Holman and Haller 2013); however, to date, the application of such systems to rip current flows has not been demonstrated (Haus 2011). The nearest example is given in Smith (2008), who uses a sophisticated acoustic system to present a single flow event (seen in Fig. 7) that is suggestive of a detached vortex produced by a rip current. An optical method that has been used frequently for rip current identification does exist (Holman et al. 2006); however, the method does not image the rip current flow field, but instead it shows an associated morphologic feature (i.e., the rip channel) through manual identification of dark features that are caused by the lack of breaking of the dominant waves in the deeper rip channels.

Marine radars can typically image waves over circular image footprints with a radius of $2-4 \mathrm{~km}$ when operating at their highest resolution and dependent on the sea state. They are commonly used for surface gravity wave imaging, but it has also been known for many years that coastal fronts and internal waves generate radar signatures (Watson and Robinson 1990; Marmorino et al. 2004; Chang et al. 2008). Descriptions of the imaging mechanism can be found in Lyzenga (1991, 1998) and Plant et al. (2010) whereby microwave radar backscatter is enhanced when short, wind-generated gravity waves are modulated by the underlying current field; backscatter is further increased by the presence of short-scale breaking waves induced by the current field.

Marine radars are incoherent radars, which means they do not have the capability of estimating the velocities of the radar scatterers being advected by rips via the Doppler shifts between the transmitted and received pulses. Coherent radars have this capability. However, Doppler shifts are a higher-order quantity; therefore, they require a longer dwell time on each patch of the ocean surface to integrate the returns. Hence, coherent radars have much 
lower sweep rates or much smaller imaging footprints $\left(10^{4} \mathrm{~m}^{2}\right.$ versus $10^{7} \mathrm{~m}^{2}$ ) and are not able to synoptically capture the full alongshore surf zone extent (Frasier et al. 1995; Plant et al. 2005). The authors are not aware of any rip current observations via shore-based coherent radar in the published literature.

Herein, marine radar observations are presented that show elongated regions of increased backscatter, mainly oriented in the cross-shore direction, extending out from the surf zone and terminating in a plume-like bulbous feature that are attributed to the rip current flow fields. Specifically, the offshore-directed surface flow of the rips interacts with the small-scale wind wave field as it exits the surf zone leading to increased surface roughness and microbreaking, which generates higher radar returns. These observations indicate that radar remote sensing can be an effective tool for detecting rip currents and provide a more synoptic picture of the rip current flow field outside the surf zone.

The paper is organized as follows: in the subsequent section, the observational data set and the radar image processing methodology are described. Next, the frequency and persistence of the rip events in relation to the nearshore morphology, incident wave forcing, and tidal elevation are detailed. In situ current data are also presented that quantify the rip current strength, confirm the identification of rip currents in the radar images, and illustrate the depth variability of the offshore flow. The in situ instruments and the remote sensor do not independently capture all of the rip current events; however, used in tandem, all of the likely (based on wave heights and tide levels) rip events were captured. Also in this section, evidence of a rip outbreak event that occurred during the observation period is presented.

In the last section, a simple calibration of the backscatter intensity is performed to quantify the backscatter variations as a result of the rip current flow and place them in context of other radar platforms. Finally, the rip imaging mechanism is discussed, and a necessary cross-shore wind stress condition for radar imaging of rip currents is identified.

\section{Data Collection}

X-band nautical radar images were collected during a pilot experiment that is part of an ongoing effort funded by the Office of Naval Research entitled Data Assimilation and Remote Sensing for Littoral Applications (Jessup et al. 2012). The radar observations from the pilot experiment span an 11-day period (September 7-17, 2010) and were collected at the U.S. Army Corps of Engineers Field Research Facility (FRF) located on the Outer Banks (Town of Duck) of North Carolina. The radar is a commercial, horizontally polarized, marine radar that operates at $9.45 \mathrm{GHz}$. It was installed on a $10-\mathrm{m}$ tower near the north end of the FRF property $(x, y=17.4,971.4 \mathrm{~m}$, antenna elevation $=13.8 \mathrm{~m}$ ). The local FRF coordinate system has the $x$-axis pointing offshore and the $y$-axis pointing approximately $18^{\circ}$ west of True North, which is shown in the simple map in Fig. 1 (a). The vertical datum is North American Vertical Datum of 1988 (NAVD88).

The radar operates at a peak $25-\mathrm{kW}$ transmitted power and has a $2.74 \mathrm{~m}$ open array antenna rotating at approximately 44 revolutions per minute, such that the ocean surface is imaged every 1.25 $\mathrm{s}(0.80 \mathrm{~Hz})$. The intrinsic resolution of the radar pulse is $12 \mathrm{~m}$; however, the data acquisition system (Imaging Science Research) internally oversamples producing an image resolution of $3 \mathrm{~m}$ in the range direction. In the azimuthal direction, seven pulses are averaged to improve the signal-to-noise ratio, which results in an approximate true azimuthal resolution of $2^{\circ}$. Further details of the system can be found in Catalán et al. (2011) along with its application to the identification of large-scale breaking waves.

Sets of 640 images were collected over periods of approximately $15 \mathrm{~min}$ beginning at the top of each hour for $24 \mathrm{~h}$ per day throughout the experiment. The images were subsequently mapped to the FRF coordinate system. Fig. 1(b) shows an example single snapshot radar image that has been cropped to the region of interest. Individual wave crests are visible in the figure, especially along the crest of the alongshore sand bar $(x=\sim 160 \mathrm{~m})$ where the waves predominantly break. However, rip currents are not easily discerned, but a region of increased backscatter intensity is evident offshore of about $y=900 \mathrm{~m}$.

Fig. 2(a) shows the corresponding uncalibrated mean intensity image, that is, the average of a 640 rotation $(\sim 800 \mathrm{~s})$ image sequence. The image contains a cross-shore oriented feature of increased backscatter intensity that is attributed to the rip current flow field. A somewhat surprising aspect of this feature is the distance offshore to which it extends, which is all the way out to $x=600 \mathrm{~m}$ for this collection period. This distance is several times the width of the surf zone because the shoreline location varied between $x=70-90 \mathrm{~m}$ and the offshore edge of the surf zone was consistently located near the bar crest $(150<x<200 \mathrm{~m})$ during our observation period.

As part of normal FRF operations, a suite of hydrodynamic and meteorological instruments are continuously deployed, and bathymetric surveys are collected frequently. During our experiment, bathymetric data were collected by the specialized amphibious vehicles of the FRF (LARC and CRAB) on September 6, 2010, and September 15, 2010. Fig. 3 shows the data from September 6 with NAVD88 as the vertical datum. Incident wave conditions were measured near the 8-m water depth contour $(x=\sim 915 \mathrm{~m})$ by a twodimensional array of bottom-mounted pressure sensors (Long 1996; unfortunately, this system is no longer operational as of February 2012), which is also shown in Fig. 3. Wind speed and direction were measured $19.5 \mathrm{~m}$ above mean sea level at the end of the FRF pier (Fig. 1). The FRF also maintains a cross-shore array of in situ current profilers (Mulligan et al. 2011). The array includes two Nortek Aquadopps (hereafter denoted adop1 and adop2) located at $(x, y, z)=(233,940,-3.3 \mathrm{~m})$ and $(375,939,-4.3 \mathrm{~m})$ and one acoustic wave and current profiler (Nortek AWAC) located at $(x, y, z)=(446,938,-5.0 \mathrm{~m})$. Their locations are indicated by the red current vectors shown in Fig. 2 and the black squares in Fig. 3. During the pilot experiment, these instruments recorded vertical profiles of bidirectional currents at $1 \mathrm{~Hz}$ in three 5-min burst collections near the end of each hour for $24 \mathrm{~h}$ per day. The vertical profiles were then averaged over the 5-min bursts (300 samples) and then were vertically averaged resulting in depthand time-averaged currents for each sensor recorded at 35, 45, and 55 min past the hour.

\section{Results}

Time series of the depth-averaged cross-shore currents measured by adop1 and adop2 and the AWAC are shown in Fig. 4(d). The rip current occurrences are clearly evident in the adop1 time series as narrow peaks of positive (offshore) velocities, and rip current strength was relatively strong $(20-40 \mathrm{~cm} / \mathrm{s})$ when present at this location. However, the two current meters furthest from shore (adop2 and AWAC) only witnessed offshore velocities greater than $20 \mathrm{~cm} / \mathrm{s}$ a couple of times and were impacted by the rips much less frequently. The mean radar images in Fig. 2 are examples from one of those times when the rip current was observed at adop2 and AWAC. As indicated by the red current vectors, on this occasion adop1 was located near the base of the rip and experienced mainly alongshore flow in the feeder current; adop2 measured the strongest offshore flow $(\sim 30 \mathrm{~cm} / \mathrm{s})$, and the AWAC appears to be in the spreading plume with offshore flow directed obliquely away from the rip head. For completeness, because the radar and current 
(a)

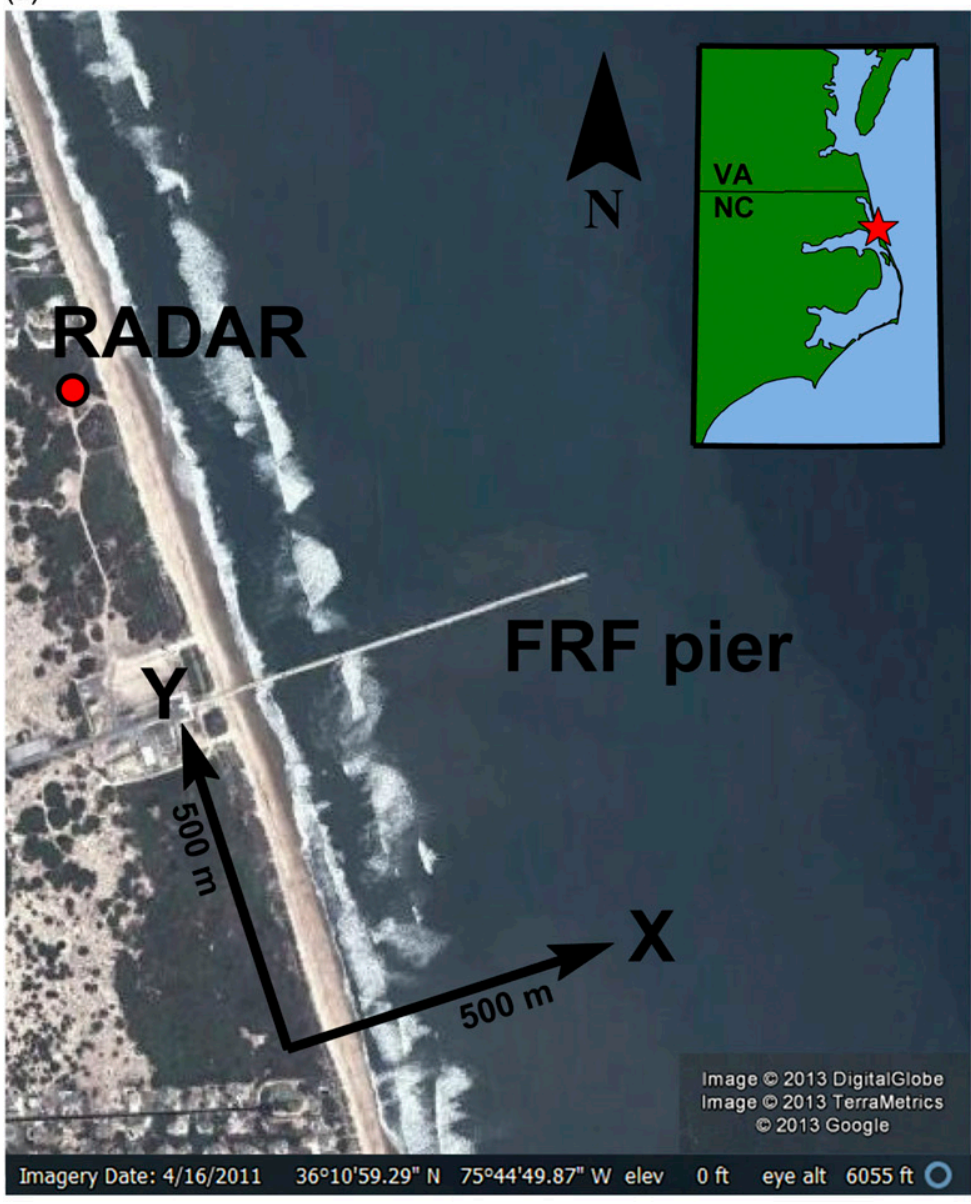

(b)

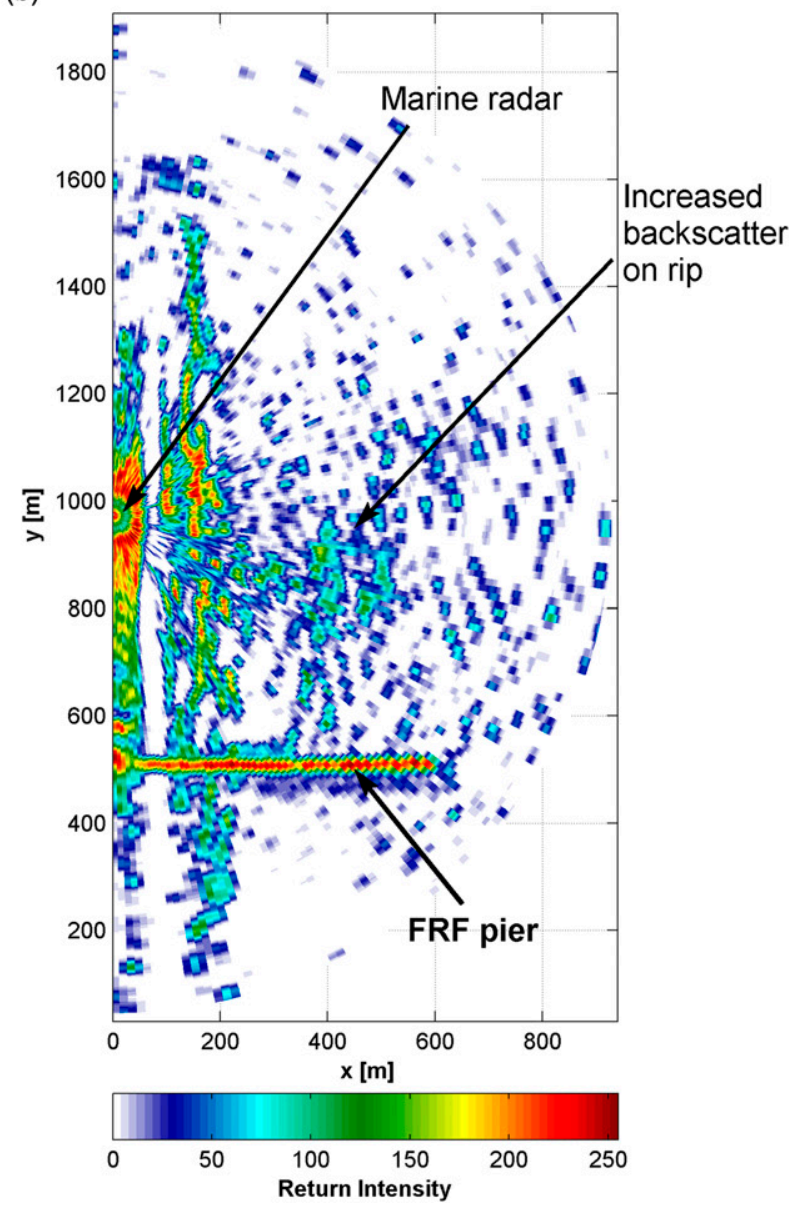

Fig. 1. (Color) (a) FRF site Duck, North Carolina, with local coordinate system (@ 2013 Google Earth, Image @ 2013 TerraMetrics, Image $\odot 2013$ DigitalGlobe); (b) raw (uncalibrated) radar snapshot image, September 10, 1:01:04 EST

measurements were not collected synchronously, the depth-averaged currents were temporally interpolated to the center of the radar collection window for the radar image overlays (i.e., from $15 \mathrm{~min}$ before the top of the hour to approximately $7 \mathrm{~min}$ after).

Mean radar images collected around low tide during the 10-day observation period consistently indicate the increased backscatter features that are attributed to rip current flows. Fig. 5 contains an example set of six mean images collected around low tide along with the depth-averaged current vectors. Each shows a rip current flowing across the bar around $850<y<950 \mathrm{~m}$. The cross-shore array of in situ current meters was fortuitously located near this location, and it is evident that the depth-averaged currents flow in a direction consistent with the rip features. It is also evident that the rips often flow offshore with some obliquity. Initial analysis of the dynamics driving rip obliquity offshore of the surf zone was presented by Haller et al. (2012) and will be addressed further in a separate work.

To quantify the frequency and persistence of the rip current events, the mean images from each of the hourly radar collections were visually evaluated for the presence of a rip feature (in the region $850<y<950 \mathrm{~m}$ ), and each event was cataloged. Fig. 4(b) shows the National Oceanic and Atmospheric Administration tide gauge record (water surface elevation with respect to NAVD88) from the end of the FRF pier, and the times where rips were identified are denoted by the thick black line segments. In total, there were 14 separate rip current events identified in the radar observations, each is approximately centered on low tide. The mean rip current duration was
$4.4 \mathrm{~h}$ with the longest event lasting $7 \mathrm{~h}$. The minimum duration was $1 \mathrm{~h}$, which means that it was evident in only one of the hourly collections (15-min duration) during that particular low tide.

The rip current at this location was remarkably frequent and is evident in the radar images for 14 out of the 19 low tides during the observation period. A visual analysis of the depth-averaged crossshore velocity records shows a similar number (14) of rip events (defined here as offshore flows $>20 \mathrm{~cm} / \mathrm{s}$ ). However, in comparing Fig. 4(b) with Fig. 4(d), there are many events that only appear in one of the sensing modalities (remote versus in situ). There are two reasons for this. The first is that data from in situ sensors have a much smaller spatial footprint. Hence, when the rip current exits the surf zone with an oblique trajectory to the southeast (i.e., away from the in situ array), the offshore flow is not captured by the in situ sensors. This is clearly evident during the three low tides occurring between 1700 hrs. Eastern Standard Time (EST) on September 10 and 1700 hrs. EST on September 11, and in Fig. 5(c). The second reason has to do with the radar imaging mechanism; this will be discussed in the next section.

The remarkable frequency of rip current events, their clear correlation with low tides, their mean duration of $\sim 4 \mathrm{~h}$, and their consistent location over a 10 -day period is very indicative of a morphologic rip forcing mechanism, and the bathymetry data confirm this. The bathymetry data (collected September 6, 2010) were interpolated onto a $1 \times 10$-m grid (cross shore and alongshore, respectively) and are shown in Fig. 3. The cross-shore transect [Fig. 3(c)] 
(a)

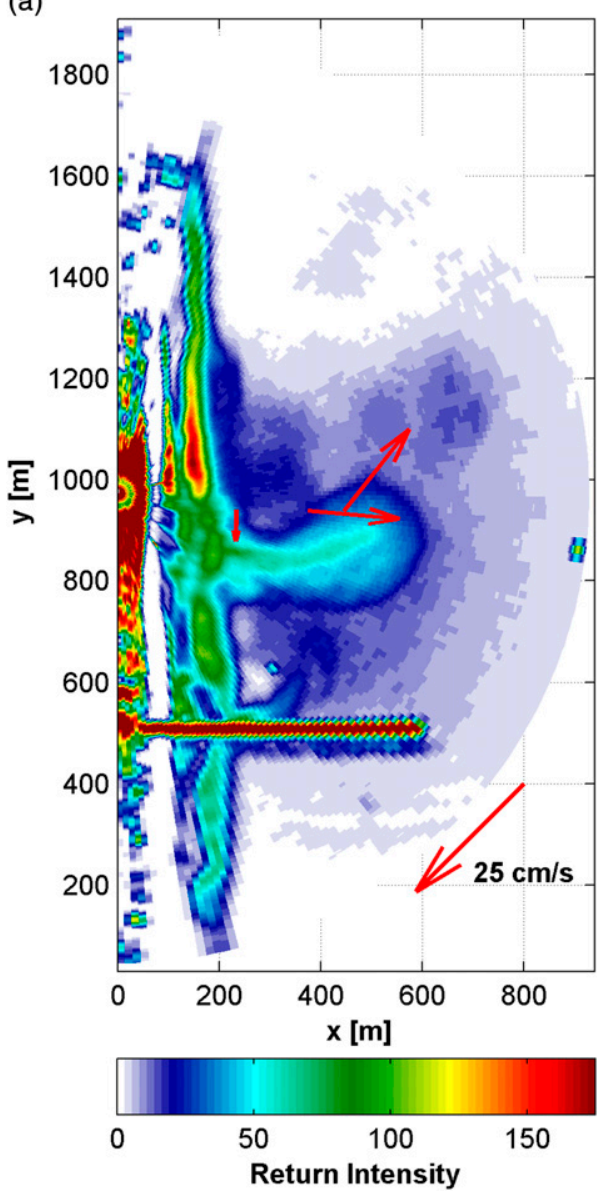

(b)

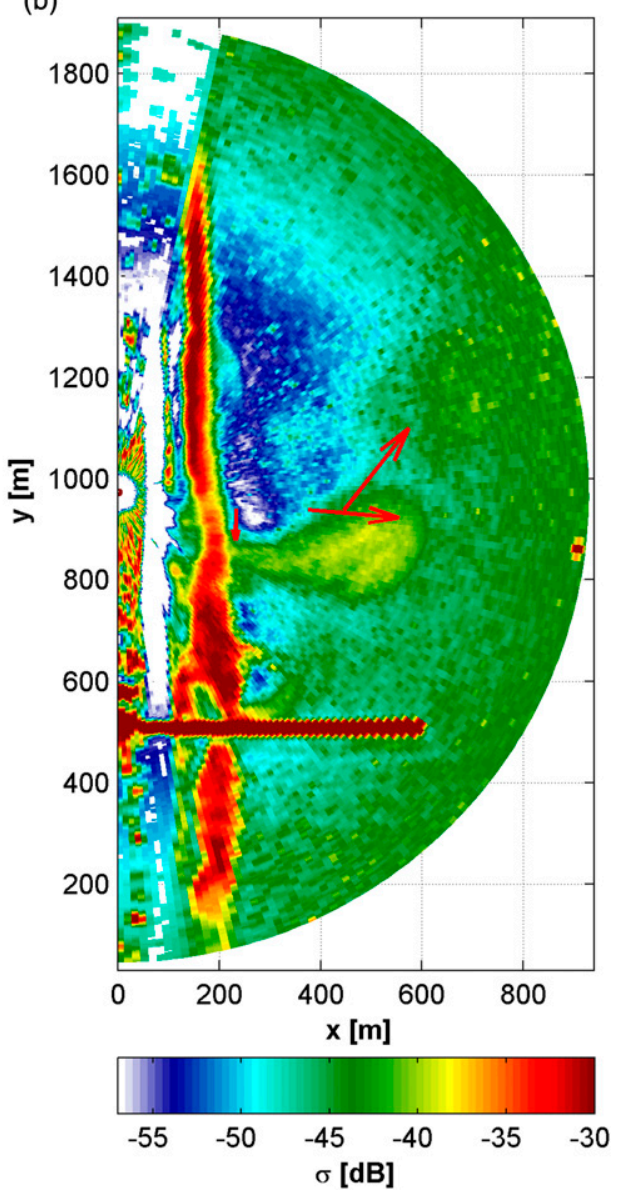

Fig. 2. (Color) (a) Uncalibrated, mean radar image with in situ current vectors (25-cm/s scale vector also shown); (b) calibrated mean radar image, September 10 at 00:59 EST

along $y=700 \mathrm{~m}$ lies to the south of the rip current location and shows a single longshore bar located between $x=150$ and $200 \mathrm{~m}$. The bathymetry map shows a large depression under the pier around $x=500 \mathrm{~m}$, and to the north and south there is evidence of a flat terrace feature at $x=250-400 \mathrm{~m}$ and $-3.5<z<4.5 \mathrm{~m}$. A transect along the bar crest $[x=160 \mathrm{~m}$, Fig. 3(b) $]$ shows there was a gap in the bar located at $y=750-1,000 \mathrm{~m}$ with the depth in the gap being about $1 \mathrm{~m}$ deeper than at the bar crest. Another bathymetric survey was conducted 9 days later on September 15 and indicated that the bar and gap were stable during the observation period.

Fig. 4(a) shows the significant wave height time series, and Fig. 6 shows the wave rose of the mean directions and peak periods during the experiment. These data were measured at the offshore array and show a mean significant wave height of $0.68 \mathrm{~m}$ and a maximum of $1.15 \mathrm{~m}$, which are typical for summer conditions at this site. Mean annual significant wave height for this region is $0.9 \mathrm{~m}$ (Birkemeier et al. 1985). The wave rose shows that the mean incident wave directions were generally mildly oblique $\left(\leq \pm 30^{\circ}\right.$ from shore normal $)$ with both wind-dominated and swell-dominated seas occurring at times. There were some limited occasions of bimodal seas as well. The most common condition was a peak period of $6-10 \mathrm{~s}$ from the east (mildly oblique).

Dusek and Seim (2013) conducted an extensive analysis of rip current occurrence at a similar nearby field site (Kill Devil Hills, NC) and found a notable increase in rip current intensity for significant wave heights exceeding $\sim 0.7 \mathrm{~m}$ (in $12 \mathrm{~m}$ depth). However, in our (albeit shorter) data record, there is evidence (either by radar, in situ, or both) for rip current occurrence during every single low tide except perhaps the one just after midnight on September 9. This includes significant wave heights as low as $0.5 \mathrm{~m}$. The two wave height thresholds from two different but similar beaches are viewed as mutually supportive, and the exact wave height threshold will of course also be dependent on the rip channel morphology and instantaneous tide level.

There were rip currents imaged via radar at locations other than the bar gap at $y=900 \mathrm{~m}$ as well. For example, there was a rip frequently observed exiting obliquely from under the FRF pier and smaller rips in the vicinity of $y=1,300$ and $1,400 \mathrm{~m}$. These were all in evidence during the rip outbreak event on September 13 when four different rips were observed within a $1-\mathrm{km}$ stretch of coast, which is shown in Fig. 7. These rips at other locations, while less frequent, were nonetheless correlated with low tides and higher waves [e.g., see $y=1,300-1,400 \mathrm{~m}$ in Fig. 8(c)]; hence, it is highly likely that these are all morphologically driven. There is additional evidence to support this conjecture, such as the known scour hole under the pier shown in Fig. 3 and the consistent morphologic evidence in the marine radar images. Careful examination of the alongshore bar near $y=1,300-1,400 \mathrm{~m}$ in the mean radar images indicates a slight sinuosity [see McNinch (2007) for an analysis of alongshore bar structure via marine radar]. Fig. 7 clearly shows the rip locations at similar phases of the slightly sinuous bar. Unfortunately, the bathymetric data do not extend out this far in the alongshore direction. Without conducting an in-depth analysis, it appears the rips at these locations require a higher significant wave height threshold before they appear. 
(a)

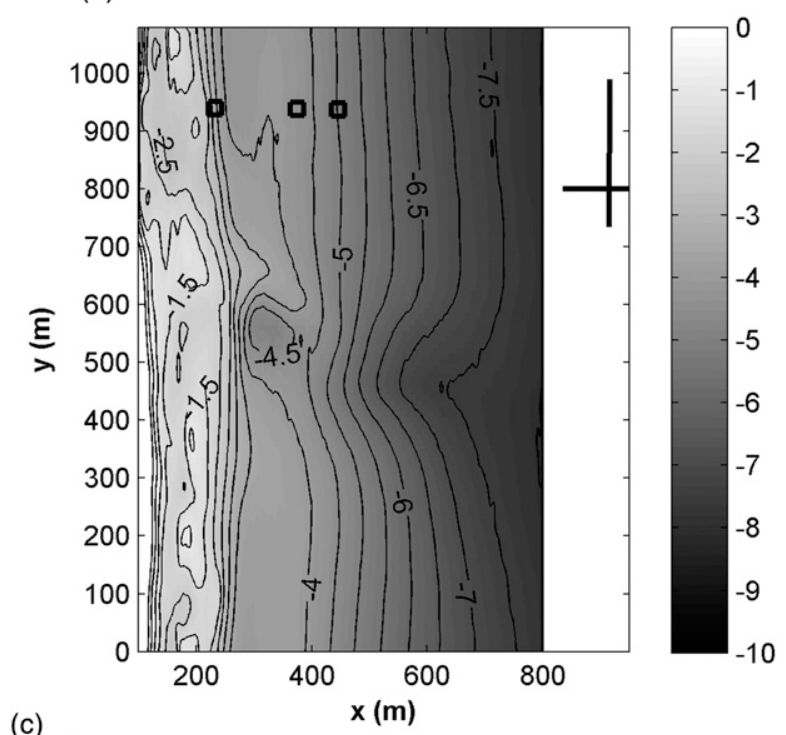

(b)

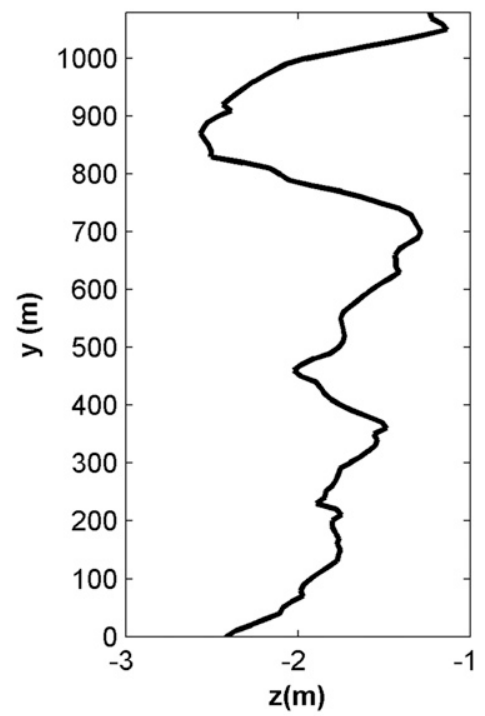

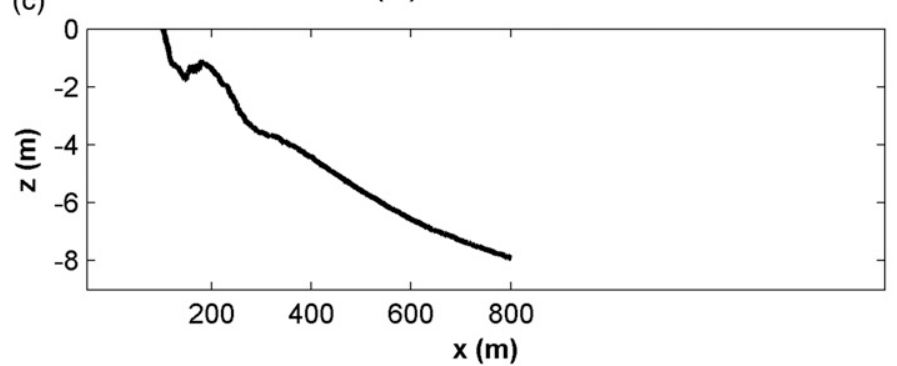

Fig. 3. (a) Bathymetry of the study area collected September 6, 2010, with in situ cross-shore instruments (adop1, adop2, and AWAC) marked by squares; the extent of the FRF offshore wave array indicated by the cross near $x=900 \mathrm{~m}$ and $y=800 \mathrm{~m}$; (b) alongshore bathymetric profile $(x=160 \mathrm{~m})$ showing the gap in the bar between $800<y<1,000 \mathrm{~m}$; (c) cross-shore profile at $y=700 \mathrm{~m}$ showing single-barred profile
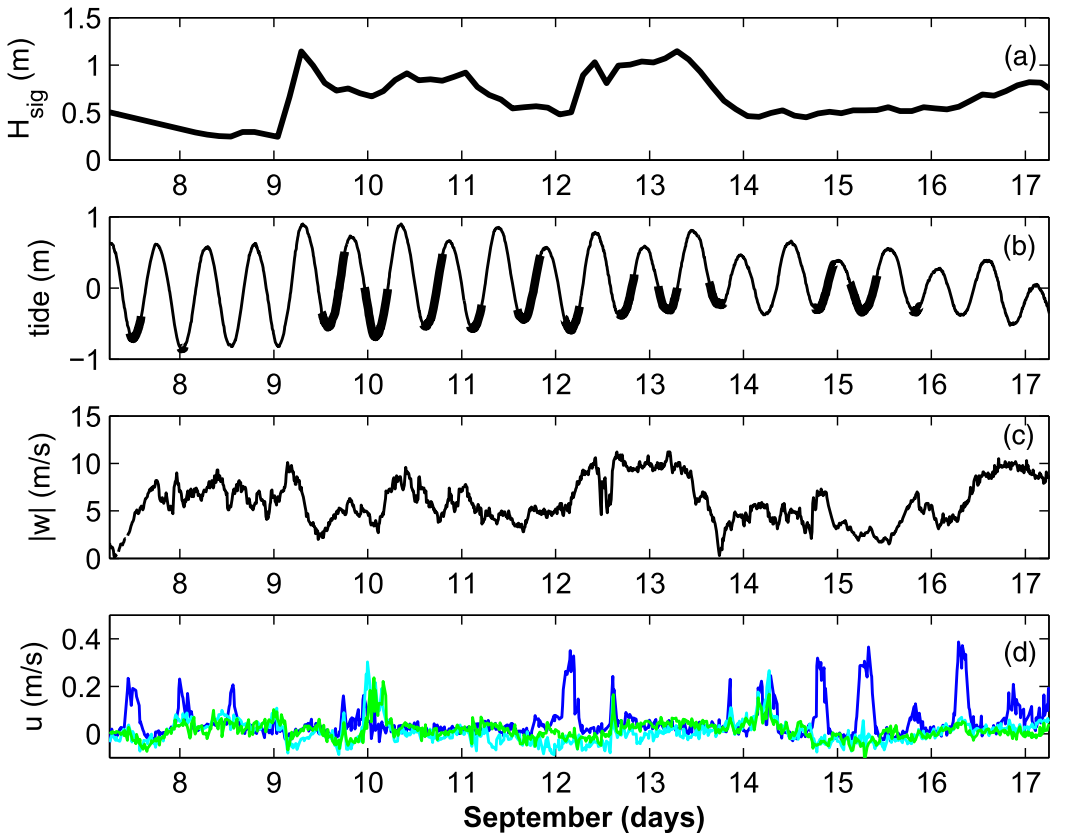

Fig. 4. (Color) Time series of (a) significant wave height measured at the 8-m array; (b) tidal elevation with respect to NAVD88; (c) wind speed; (d) cross-shore velocities, adop1 (blue), adop2 (cyan), AWAC (green) 

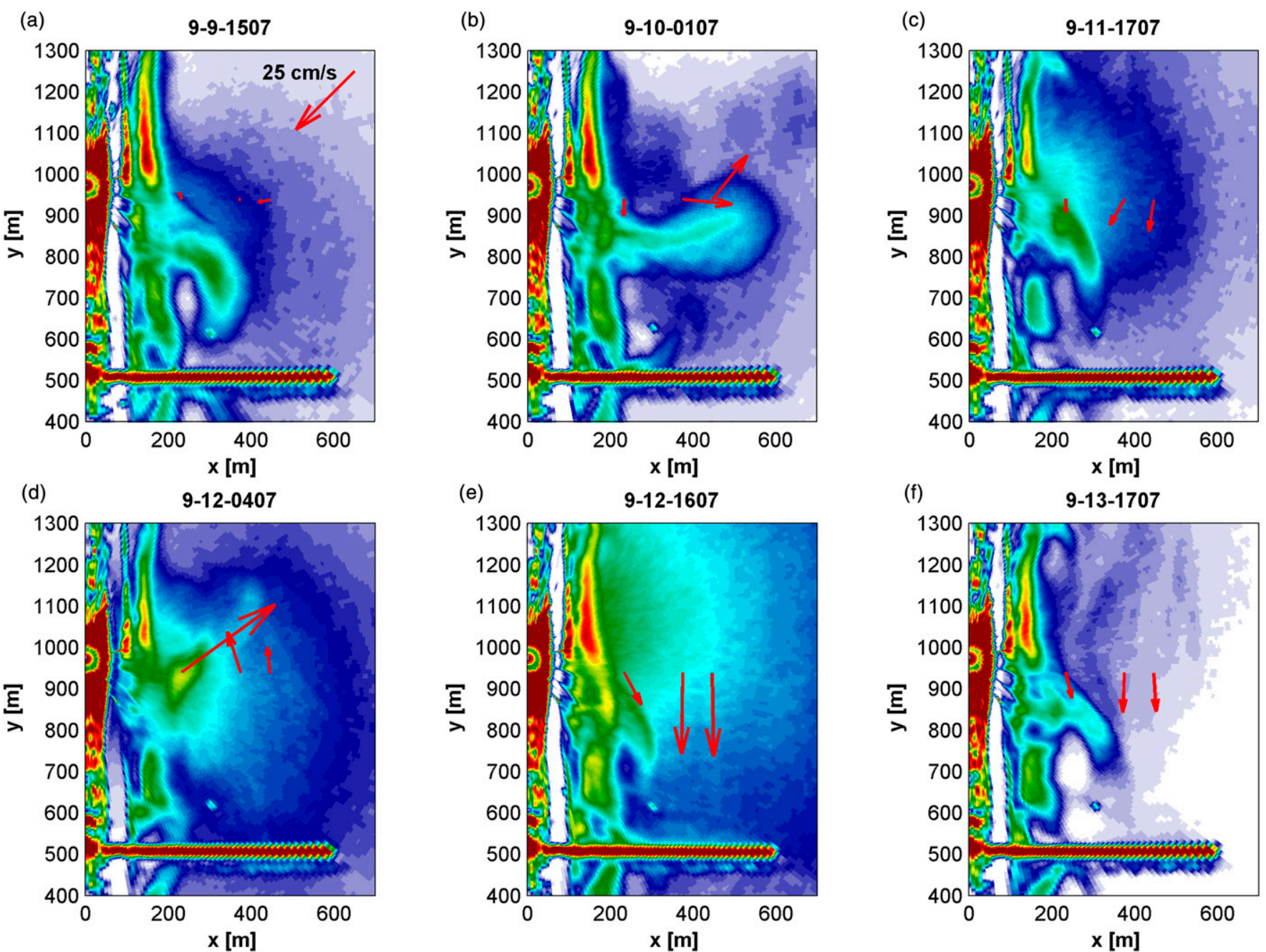

(e)
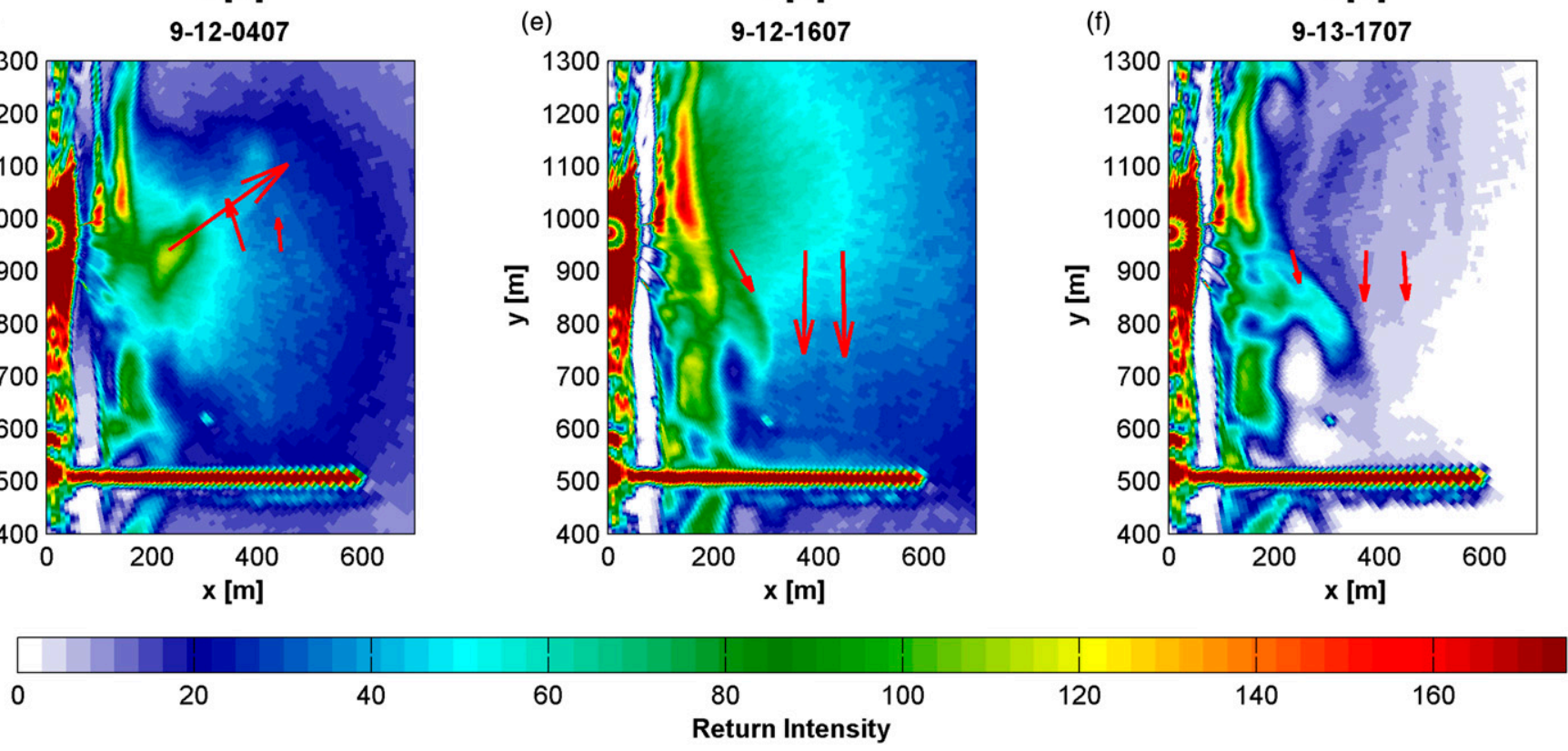

Fig. 5. (Color) Example mean radar images from low-tide rip events; month-day-time EST: (a) shows a 25-cm/s scale vector

\section{Imaging Conditions}

It is well established that the presence of current convergences will lead to modulations in the short, wind-generated wave field creating a rougher sea surface, which leads to increased radar backscatter. The backscatter is further enhanced if the current field induces breaking of the short waves as well (Plant et al. 2010). The authors postulate that the same phenomena are responsible for the increased backscatter observed on the portion of the rip current flow field that resides offshore of the surf zone (i.e., in regions away from the breaking of the dominant waves).

For comparison across other radar sensors, a simple calibration of the radar system was performed. Using the known radar cross section of a backscatter target, the cross-calibration transfer function

$$
\sigma=\beta_{1} I+\beta_{2}+10 \log _{10}\left(R^{3}\right)-10 \log _{10}(\cos \theta)
$$

was calculated via a least-squares fit. Here, $\sigma$ is the normalized radar cross section (NRCS; in decibels), $I$ is the measured return intensity $(0-1,020), R$ is the slant range (m) from the antenna to the water surface pixel, $\theta$ is the associated vertical slant angle (limits to
0 degrees at the horizon), and the calibration constants $\beta_{1,2}$ were determined during a previous experiment (as described in Catalán et al. 2011) and assumed to be unchanged for the present work. All equipment, antenna position, and relevant collection parameters were the same here as in the previous experiment. For completeness, a calibrated mean radar image is shown in Fig. 2(b). The NRCS levels of -40 to $-35 \mathrm{~dB}$ in the region of the rip current are significantly lower than what would be expected in the presence of large-scale breaking waves (Catalán et al. 2011). This supports the postulate that it is the modulation and breaking of shorter-scale waves that are responsible for the increased backscatter on the rip current.

In addition, it was determined that the rip current velocities were not confined to an atypically narrow surface area whereby the backscatter feature would be overemphasizing the local hydrodynamic importance of the rip flow. Fig. 8 shows the measured vertical velocity profiles from adop1 [Figs. 8(a) and (d)] and AWAC [Figs. 8(b) and (e)] for two different rip events. The profiles represent approximately 1.5-h mean currents (six 5-min burst samples) for particular rip events during which the rip was in the neighborhood of the in situ array. Fig. 8(a) shows the rip current to extend through approximately $2 / 3$ of the water column as it flows past adop 1 


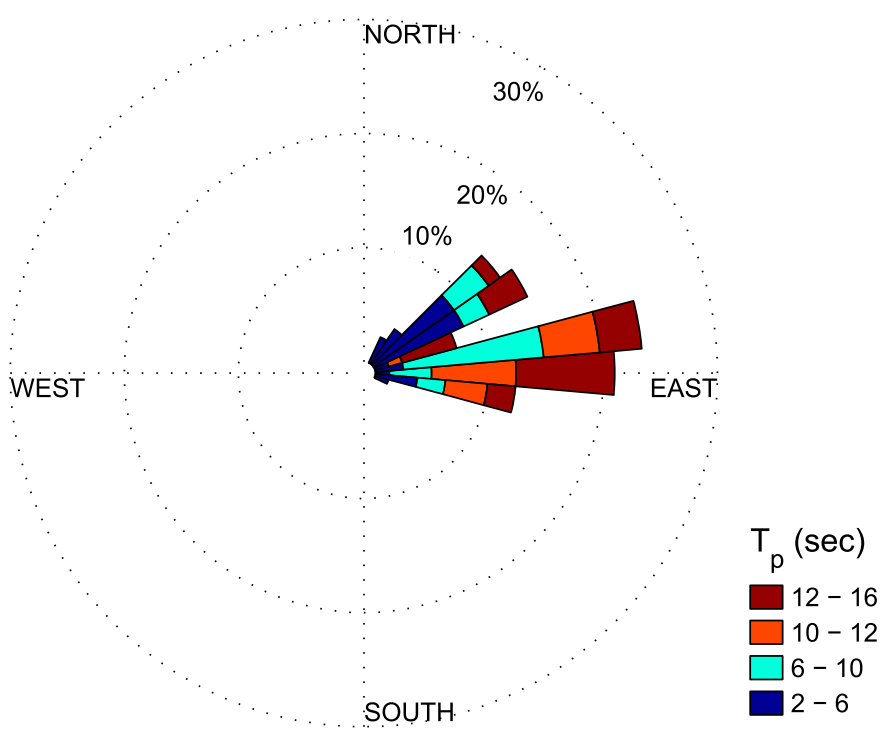

Fig. 6. (Color) Wave rose showing the distribution of the mean incident wave directions recorded at the FRF 8-m array during the pilot experiment

( $x=233 \mathrm{~m})$. Fig.8(e) shows fairly substantial offshore flow $(\sim 20 \mathrm{~cm} / \mathrm{s})$ at the AWAC location $(x=446 \mathrm{~m})$ that also extended through $2 / 3$ of the water column. These profiles are similar to those observed in rip currents by MacMahan et al. (2005), for example.

These data also illustrate the additional insight gained by the synchronous combination of in situ and remote sensing data. For example, the in situ data from the September 15 event [Figs. 8(a-c)] would suggest that the rip current does not extend as far as the AWAC; in fact, the radar image shows that the rip current has turned to the north and was simply not captured by the AWAC. The September 10 example [Figs. 8(d-f)] shows that the rip can extend as far as $x=600 \mathrm{~m}$ (Figs. 2 and 5). This distance is several surf zone widths from shore. It is possible that the flat terrace immediately offshore of the rip channel (as previously discussed) enables the rip to extend further offshore than it normally might; however, the slope between $x=400-600 \mathrm{~m}$ is a typical $1: 100$ as shown in Fig. 3 . Therefore, the morphology is not particularly unique for this location.

A question remains regarding why the rip current is sometimes not observed in the radar images even though a rip appears in in situ data (see September 8, 14, and 16 in Fig. 4). It does not appear that the missing rip currents in the radar images are the result of a lack of rip strength during those events. Instead, examination of the crossshore component of the wind stress, shown in Fig. 9, demonstrates that the radar imaging of rip currents is dependent on the cross-shore wind stress. The wind speed time series is shown in Fig. 4(c); wind speeds were consistently above $2 \mathrm{~m} / \mathrm{s}$, and the observed maximum was $11 \mathrm{~m} / \mathrm{s}$ on September 13. The wind speed and direction data were used to calculate the cross-shore wind stress using the method of Large and Pond (1981). In Fig. 9, when the cross-shore wind stress is positive (offshore winds) and greater than $\sim 0.02 \mathrm{~m} / \mathrm{s}^{2}$, these lowtide morphologic rips are not imaged by the radar. This is a result of the decreased wind-generated short-scale waves because of the short fetch during offshore winds and the lack of a steepening modulation effect when the short-scale waves are traveling with the rip current rather than against it.

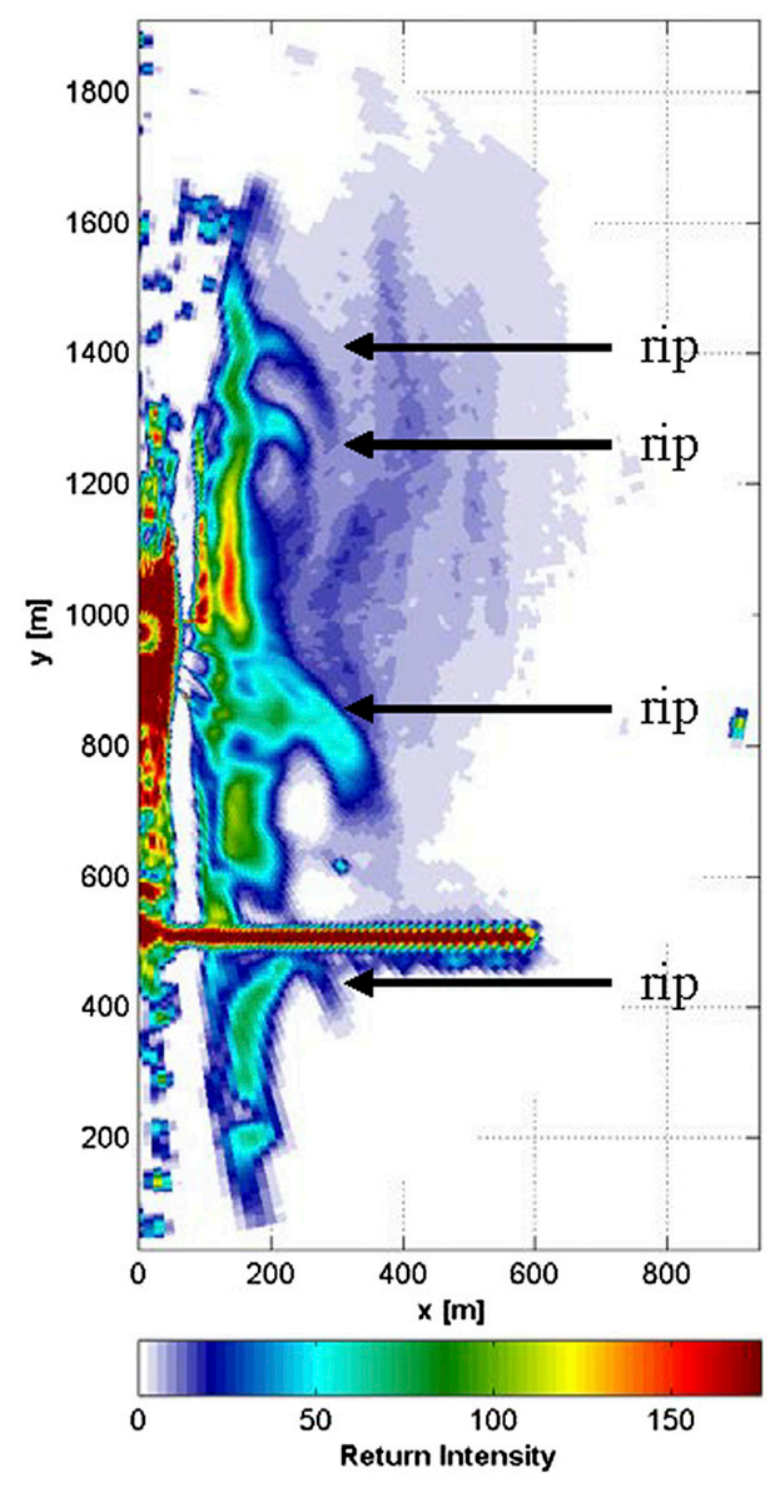

Fig. 7. (Color) Mean radar image showing rip outbreak event, September 13, 16:59 EST

\section{Summary and Conclusions}

New observations of rip currents obtained by marine radar are presented and demonstrate a regular sequence of low-tide, morphologically driven rip events over a 10-day period on a beach with alongshore bar/trough morphology. The data also contain several rip outbreak events where four separate rips were imaged over a $1-\mathrm{km}$ stretch of coast. The remote sensing observations were corroborated with in situ data and demonstrate a new, effective tool for rip current identification over kilometer-scale stretches of coast. In contrast, extensive arrays of in situ current meters can often miss rip current events. For example, in their work at this same field site, Feddersen and Guza (2003) noted a "striking" lack of observed rips from the extensive in situ array that was deployed during the SandyDuck field experiment. In addition, herein it is shown that a combined analysis of both radar image data and in situ observations leads to a more complete picture of the spatial distribution of the rip current flow field and the rip behavior. For example, the present observations are ideal for identifying the time of obliquely oriented rip current trajectories. 
(a)

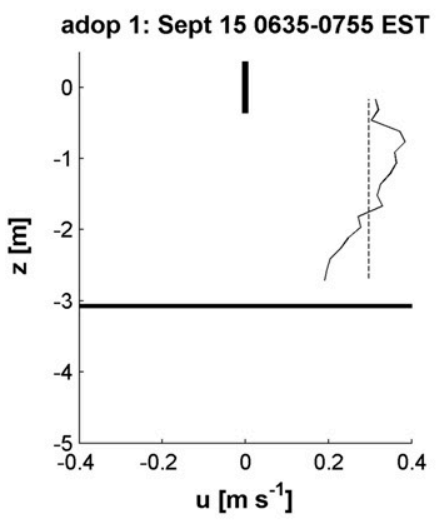

(b)

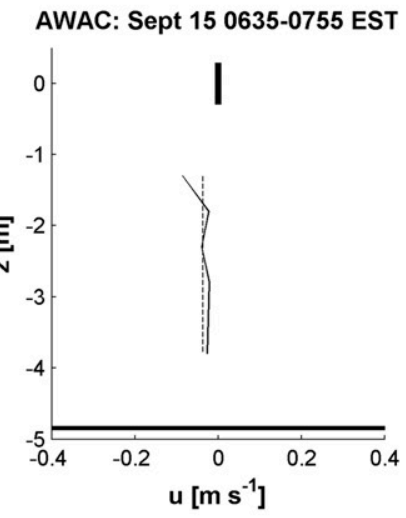

(c)

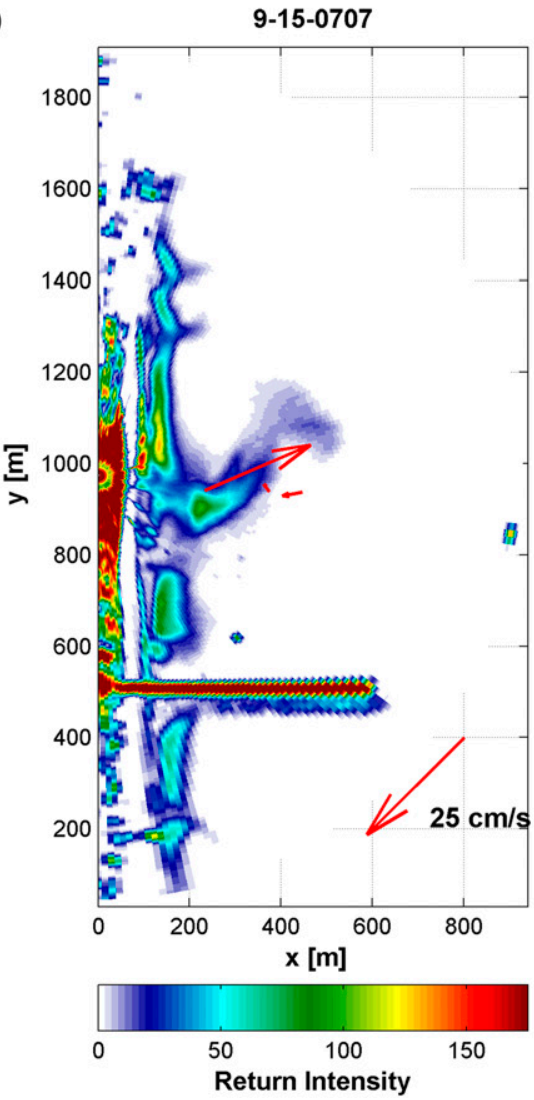

(d)

(e)
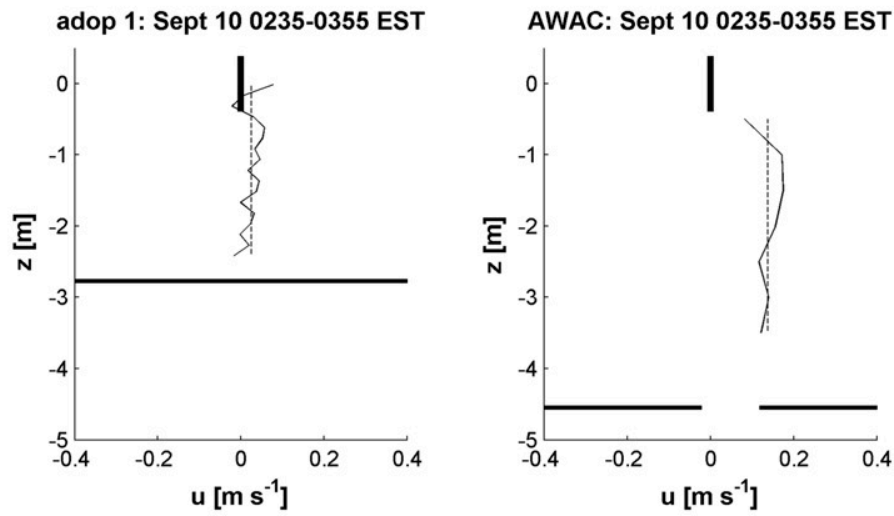

(f)

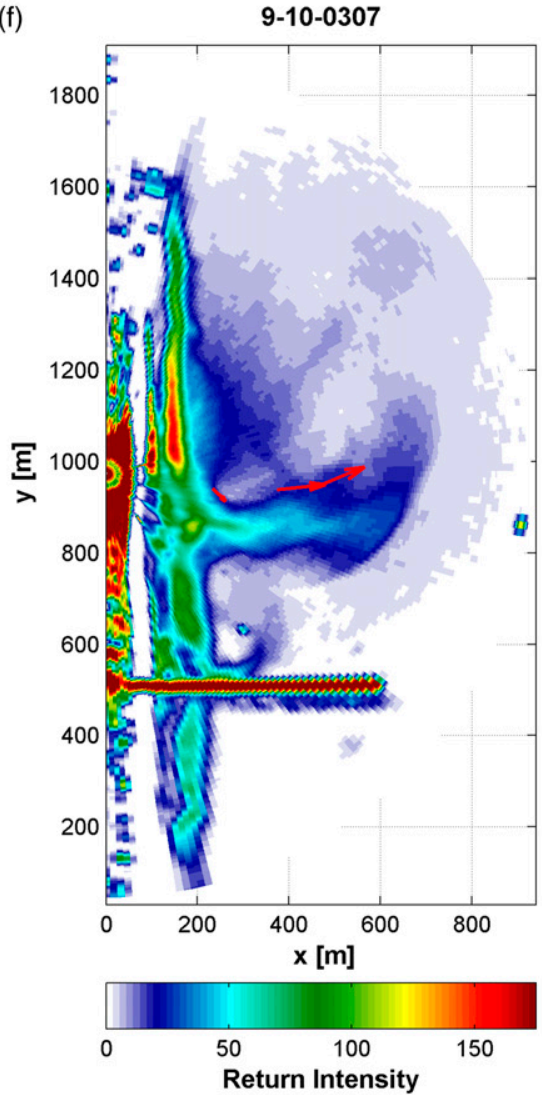

Fig. 8. (Color) (a)-(c) September 15, approximately 07:00 EST; (d)-(f) September 10 approximately 03:00 EST: mean (1.5 h) vertical profiles of crossshore current for adop 1 [(a) and (d)] and AWAC [(b) and (e)]; vertical line demarcates estimated wave excursion, thick horizontal line indicates local mean bottom depth, and vertical dashed line indicates depth-averaged mean current; (c) and (f) mean radar image and depth-averaged current vectors approximately corresponding to the center of the 1.5 -h time window for the vertical profiles

For these observed morphologic rip currents, the measured depth-averaged rip current velocities were $20-40 \mathrm{~cm} / \mathrm{s}$ whereas significant wave heights were $H_{s}=0.5-1 \mathrm{~m}$. These rip currents extended several surf zone widths from shore and persisted for periods of several hours with one event lasting for seven continuous hours. This is in contrast with some recent observations obtained via drifters that have suggested that rip flows only infrequently squirt offshore (Reniers et al. 2009; MacMahan et al. 2010) and are mostly contained within recirculating gyres.

Based on the analysis of the vertical profiles of the cross-shore currents, the radar signature of the rip current is likely because of the offshore flow in the top $2 \mathrm{~m}$ of the water column interacting with the short-scale wind-generated waves leading to increased roughness and microbreaking. This imaging mechanism is supported by the approximately calibrated NRCS levels of the rip current feature, which are below levels associated with largescale breaking waves but above background levels associated with nonbreaking waves. Also, in support of the imaging mechanism, analysis of the wind data led to the identification of a threshold offshore-directed wind stress $\left(\sim 0.02 \mathrm{~m} / \mathrm{s}^{2}\right)$ above which the rip currents were not imaged.

Finally, this observational method should be equally transferable to other field sites. The authors have plans to further test the method at other sites and in other wave conditions, such as West Coast swell 
(a)

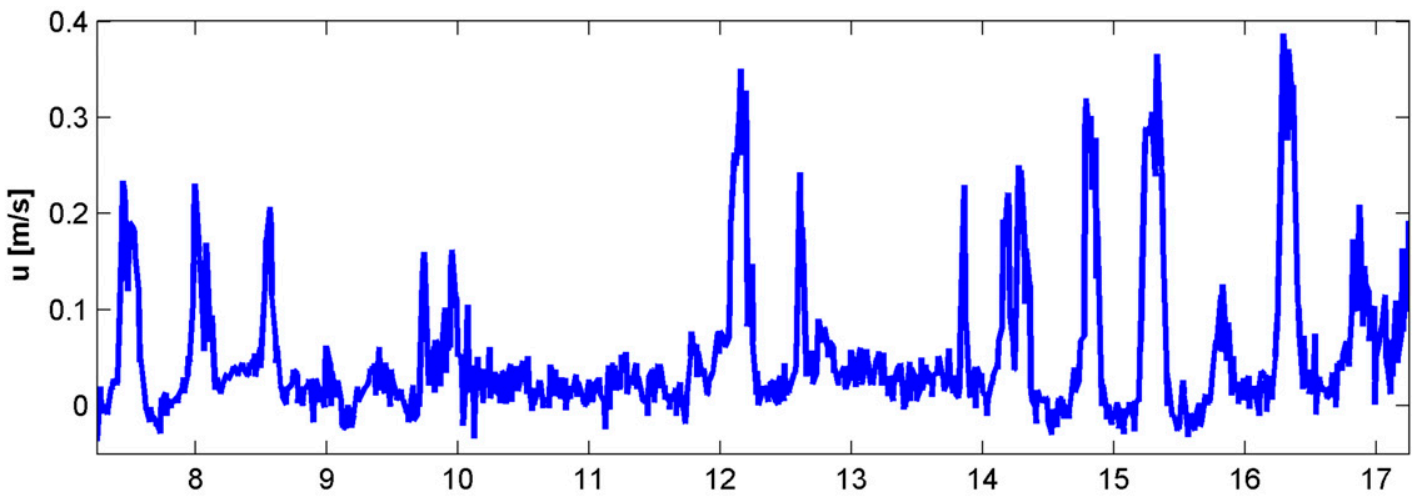

(b)

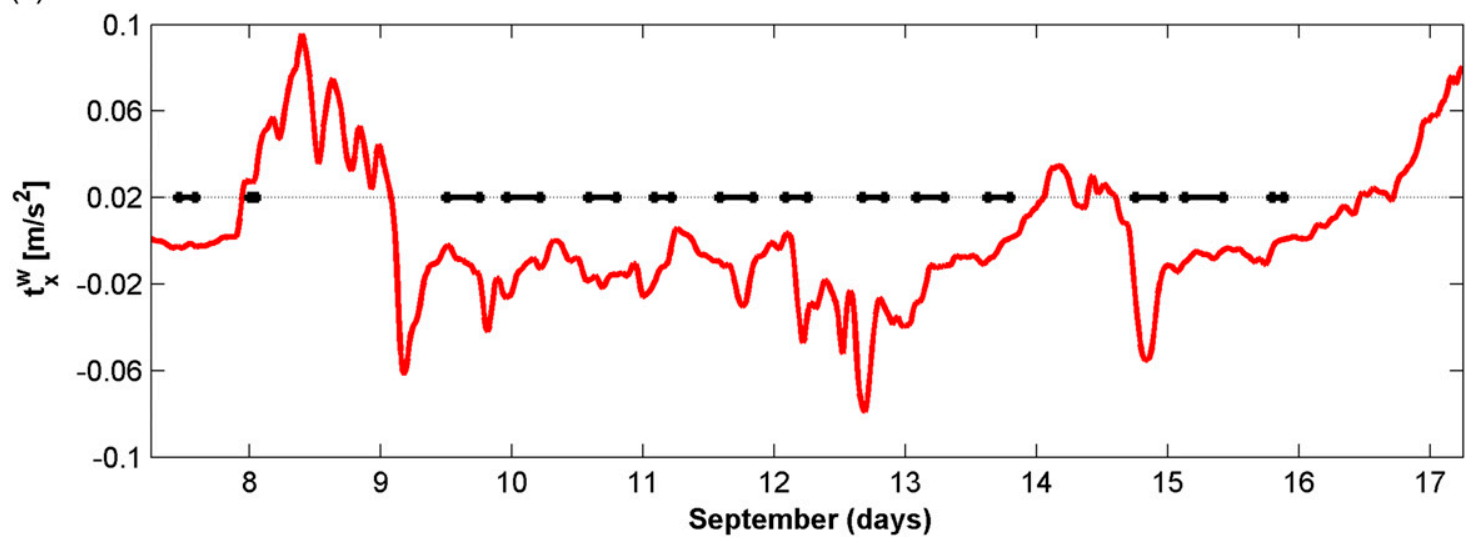

Fig. 9. (Color) (a) Cross-shore velocity measured at adop1; (b) cross-shore wind stress from the end of the pier; thick black line segments indicate time periods where rips were observed in the mean radar images

on dissipative beaches. It is suspected that one key aspect of the method is that there needs to be significant contrast in the radar returns between the unbroken waves and the roughened surface in the rip current offshore of the surf zone. Therefore, for example, the method may fail when the wind speeds pass a certain threshold because of widespread whitecapping.

\section{Acknowledgments}

We thank Kent Hathaway, Jesse McNinch, Jeff Hanson, and the staff at the Field Research Facility, Field Data Collections and Analysis Branch, U.S. Army Corps of Engineers for providing the in situ data and for their overall support during field activities. This work was funded through Office of Naval Research (ONR) Grant No. N00014-10-1-0932. P. Catalan was partially funded by ONR Global Grant No. N6290910-1-4061 and Comisión Nacional de Investigación Científica y Tecnológica de Chile (CONICYT) Grant Nos. FONDECYT-1120878 and FONDAP-15110017 and Basal Project FB0821.

\section{References}

Birkemeier, W. A., Miller, H. C., Wilhelm, S. D., DeWall, A. E., and Gorbics, C. S. (1985). "A user's guide to the Coastal Engineering Research Centers (CERC's) Field Research Facility." Instruction Rep. No. ERC-85-1, U.S. Army Engineer Waterways Experiment Station, Vicksburg, MS.

Catalán, P. A., Haller, M. C., Holman, R. A., and Plant, W. J. (2011). "Optical and microwave detection of wave breaking in the surf zone." IEEE Trans. Geosci. Rem. Sens., 49(6), 1879-1893.

Chang, M.-H., Lien, R.-C., Yang, Y. J., Tang, T. Y., and Wang, J. (2008). "A composite view of surface signatures and interior properties of nonlinear internal waves: Observations and applications." J. Atmos. Ocean. Technol., 25(7), 1218-1227.

Dalrymple, R. A., MacMahan, J. H., Reniers, A. J. H. M., and Nelko, V. (2011). "Rip currents." Annu. Rev. Fluid Mech., 43, 551-581.

Dusek, G., and Seim, H. (2013). "Rip current intensity estimates from lifeguard observations." J. Coast. Res., 29(3), 505-518.

Feddersen, F., and Guza, R. T. (2003). "Observations of nearshore circulation: Alongshore uniformity." J. Geophys. Res., 108(C1), 6 1-6-10.

Fletemeyer, J., and Leatherman, S. (2010). "Rip currents and beach safety education." J. Coast. Res., 26(1), 1-3.

Frasier, S. J., Liu, Y., Moller, D., McIntosh, R. E., and Long, C. (1995). "Directional ocean wave measurements in a coastal setting using a focused array imaging radar." IEEE Trans. Geosci. Rem. Sens., 33(2), $428-440$.

Haller, M. C., Honegger, D. A., and Catalán, P. A. (2012). "Radar observations of rip currents (Duck, NC)." Proc., 2012 Fall Meeting, American Geophysical Union, Washington, DC.

Haus, B. K. (2011). "Remote sensing applied to rip current forecasts and identification." Chapter 8, Rip currents: Beach safety, physical oceanography, and wave modeling, J. Fletemeyer, ed., CRC Press, Boca Raton, FL, 133-145.

Holman, R. A., and Haller, M. C. (2013). "Nearshore remote sensing." Аnnu. Rev. Mar. Sci., 5, 95-113.

Holman, R. A., Symonds, G., Thornton, E. B., and Ranasinghe, R. (2006). "Rip spacing and persistence on an embayed beach." J. Geophys. Res., 111(C1), C01006.

Jessup, A., et al. (2012). "DARLA: Data assimilation and remote sensing for littoral applications." Proc., 2012 Fall Meeting, American Geophysical Union, Washington, DC, Abstract OS14A-01.

Johnson, D., and Pattiaratchi, C. (2004). "Transient rip currents and nearshore circulation on a swell-dominated beach." J. Geophys. Res., 109(C2), C02026. 
Large, W. G., and Pond, S. (1981). "Open ocean momentum flux measurements in moderate to strong winds." J. Phys. Oceanogr., 11, 324-336.

Long, C. E. (1996). "Index and bulk parameters for frequency-direction spectra measured at CERC Field Research Facility, June 1994 to August 1995." Miscellaneous Paper No. CERC-96-6, U.S. Army Eng. Waterw. Exp. Stn, Vicksburg, MS.

Lyzenga, D. R. (1991). "Interaction of short surface and electromagnetic waves with ocean fronts.” J. Geophys. Res., 96(C6), 10765-10772.

Lyzenga, D. R. (1998). "Effects of intermediate-scale waves on radar signatures of ocean fronts and internal waves." J. Geophys. Res., 103(C9), 18759-18768.

MacMahan, J. H., et al. (2010). "Mean Lagrangian flow behavior on an open rip-channeled beach: a new perspective." Mar. Geol., 268(1-4), 1-15.

MacMahan, J. H., Thornton, E. B., Stanton, T. P., and Reniers, A. J. H. M. (2005). "RIPEX: Observations of a rip current system." Mar. Geol., 218(1-4), 113-134.

Marmorino, G. O., et al. (2004). "Onshore propagation of a buoyant ocean front observed using a shore-based marine radar." Cont. Shelf Res., 24(9), 951-964.

McNinch, J. E. (2007). "Bar and Swash Imaging Radar (BASIR): A mobile $\mathrm{X}$-band radar designed for mapping nearshore sand bars and swashdefined shorelines over large distances." J. Coast. Res., 23(1), 59-74.
Mulligan, R. P., Hanson, J. L., and Hathaway, K. K. (2011). “Observations of wave breaking and surf zone width from a real-time cross-shore array of wave and current sensors at Duck, N.C." Proc., IEEE/OES/ CWTM 10th Current, Waves and Turbulence Measurements (CWTM), J. Rizoli White and A. J. Williams, 3rd, eds., IEEE, Piscataway, NJ. 130-137.

Plant, W. J., Keller, W. C., and Hayes, K. (2005). "Measurement of river surface currents with coherent microwave systems." IEEE Trans. Geosci. Rem. Sens., 43(6), 1242-1257.

Plant, W. J., Keller, W. C., Hayes, K., Chatham, G., and Lederer, N. (2010). "Normalized radar cross section of the sea for backscatter: 2. Modulation by internal waves." J. Geophys. Res., 115(C9), C09033.

Reniers, A. J. H. M., et al. (2009). "Surf zone retention on a rip-channeled beach.” J. Geophys. Res., 114(C10), C10010.

Scott, T., Russell, P., Masselink, G., and Wooler, A. (2009). "Rip current variability and hazard along a macro-tidal coast.” J. Coast. Res., Special Issue No. 56, 895-899.

Smith, J. (2008). "Vorticity and divergence of surface velocities near shore." J. Phys. Oceanogr., 38(7), 1450-1468.

Watson, G., and Robinson, I. S. (1990). "A study of internal wave propagation in the Strait of Gibraltar using shore-based marine radar images." J. Phys. Oceanogr., 20(3), 374-395. 